\title{
Essay
}

\section{Dog stories and why they matter}

\section{Karla Armbruster}

Karla Armbruster is Professor of English at Webster University in St. Louis, Missouri. Her research focuses on ecocriticism and animal studies, with a special interest in literary representations of dogs.

Email: armbruka@webster.edu

Visiting Stellenbosch for the conference that gave rise to this volume of essays, I was sometimes asked what had brought me so far from my home in the United States. Each time I explained to the owner of a guest house or a tour guide that I was speaking at a conference on dogs in southern African literature, I found myself slightly self-conscious, wondering to what degree I needed to defend dogs as a legitimate scholarly subject. Especially in wealthy societies where dogs are sometimes treated as disposable accessories, they can seem a frivolous pastime: toys for children or fodder for funny or cute Internet postings, but not a topic for serious attention, except perhaps when dogs are abused or injure a human. This general discomfort with taking our canine companions too seriously reveals itself, for example, in the headlines of news stories on dog-related issues, which almost always involve word play, such as "A Tale of Wags to Riches," or "Hot Dog! Vets Say Burned Feet Common for Dogs." It's as if the writers want their readers to know they understand their topic is a little silly, a little less important than stories about humans or even more dignified animals such as wildlife.

Perhaps it is the dog's ubiquity that works against its status as an important topic; according to canine ethologist Adam Miklósi, dogs are present in almost every society around the world (71). The lives of many of these dogs look quite different from those we see in Westernised, "first world" nations: in What Is a Dog?, Ray and Lorna Coppinger point out that over $75 \%$ of the world's dogs exist outside human homes, whether loosely owned by individuals, ranging freely as village dogs, or living a feral existence on the outskirts of human settlements. Nevertheless, dogs' lives are always somehow entwined with those of humans; as the Coppingers explain, humans provide dogs' ecological niche, and they cannot exist without us. And given current estimates that dogs evolved from wolves $20,000-40,000$ years ago, they have surely influenced the evolution of humans as a species in turn. For this reason, Donna Haraway calls the dog a "companion species" that makes "life for humans what it is" (15). In On God and Dogs, theologian 
Stephen Webb notes the remarkable number of creation myths from "primordial peoples" that portray God as having a dog, with no explanation of where the dog came from. Since our deities are often imagined in our own, human image, it's tempting to think that these gods with their dogs reflect a sense that dogs have been by humans' sides since the beginning of time-a pairing so natural and necessary that the origin of the dog need not even be explained. Even today, many people still rely on dogs for help with hunting, herding, and protection, not to mention the growing numbers who find that canine companionship can alleviate crippling loneliness and even provide a way to connect with other human beings and lend a sense of purpose to life.

Because of our ancient, intimate relationship, dogs can tell us a great deal about ourselves. As the first domesticated animal and the species often seen as closest to human beings, the dog occupies a conceptual border zone between nature and culture. Thus, dogs-both real and textual — tap into all of our complex feelings about our relationship with other animals and the rest of nature. Their liminality gives them the potential to help humans re-connect with nature. All too often, though, as many essays in this groundbreaking collection demonstrate, dogs' entanglement with humanity means they get caught up in our power struggles, whether with the natural world or with each other. Just as dogs aided—often brutally-in the processes of colonisation, dogs in literary texts can perform the cultural work of upholding dominant ideologies. Some of the most popular dog stories, such as the US classic Old Yeller or South Africa's well-known Jock of the Bushveld, reinforce prevailing assumptions regarding the superiority of the human species and the rightness of the human battle to dominate nature, while also affirming the notion that domesticated animals exist to serve the interests of human beings rather than to pursue their own. Frequently, such stories also push indigenous people and other marginalised groups of humans into the category of "nature" to be controlled.

Dogs themselves can be victims of these conflicts when they don't conform to expectations or are associated with a marginalised or persecuted group of humans. The ways dogs reflect and suffer from human racial and class divides is illustrated powerfully in J. M. Coetzee's Disgrace when the purebred dogs boarded in a kennel-"working dogs", temporarily off-duty from their jobs providing security for the wealthy, white upper class and their property-are shot and killed by young black men during a farm attack. Valued and cared for due to their usefulness to socially powerful humans, the dogs also suffer for this association when the oppressed strike back. And the unwanted, mixed breed dogs that the main character, David Lurie, eventually helps to euthanise at a shelter experience the same social marginalisation as people of mixed or devalued race.

The essays in this volume don't romanticise dog-human relationships or shy away from the darker implications of our history (and potential future) together. 


\section{Essay | Dog stories and why they matter}

However, many of them also suggest ways that dogs might lead us down new paths, away from binary thinking and the desire for certainty and the need to try to control the world around us. In many of the literary texts discussed, dogs take on particular significance during times of turmoil, whether personal, political, or ecological. In addition to aiding, committing, and suffering the violence that often accompanies this turmoil, dogs sometimes offer the possibility of a different perspective, one that transgresses or transcends boundaries, even that most entrenched wall that we often build around human culture and identity to separate ourselves from other animals. Though humans often demand that dogs choose a side-nature or culture, oppressors or oppressed-both in real life and the stories we tell, dogs themselves are adaptable, complex, and often unpredictable, as are some of the best literary texts about them. As this collection demonstrates, taking dogs seriously can not only help us understand humanity from a new perspective, but it can also help us achieve the goal expressed by animal studies critics such as Cary Wolfe: to radically reconceptualise "the human" by unmasking the trace of the animal/nonhuman at its core or, more simply, to see the animal within the human rather than assuming a firm dualism between the two. Paradoxically, literature that explores dogs in their mystery, wildness, and diversity can even expand our understanding of language-so often assumed to be the marker that distinguishes humans from all other species-so that we see it as just one of many forms of multi-species communication.

In other words, it is when dogs challenge our expectations for domesticated animals-when they disobey, destroy, run wild, or otherwise confront us with their autonomy - that they hold the most potential to lead us out of our limited anthropocentric modes of experiencing the world. The American naturalist, writer and activist John Muir saw his relationship with Stickeen, a small mixedbreed dog with whom he shared a dramatic adventure on a glacier during an 1880 trip to Alaska, as the key to a new perspective on the rest of nature, writing that "Our storm-battle for life brought him to light, and through him as through a window I have ever since been looking with deeper sympathy into all my fellow mortals [a phrase which the biocentric Muir surely intended to evoke nonhuman species]" (73). As a species, human beings have shared many battles (literal and figurative) with dogs, and no doubt we will continue to do so. If we let them, they can help us better understand and appreciate not just our own natures but also those of the countless nonhuman beings with whom we share this planet.

July 31,2018 
Essay | Dog stories and why they matter

\section{WORKS CITED}

Coppinger, Raymond \& Lorna Coppinger. What Is a Dog? U of Chicago P, 2016.

Haraway, Donna J. The Companion Species Manifesto: Dogs, People, and Significant Otherness. Prickly Paradigm / U of Chicago P, 2003.

Miklósi, Adam. Dog Behavior, Evolution, and Cognition. $2^{\text {nd }}$ ed. Oxford U P, 2015.

Muir, John. Stickeen: The Story of a Dog. Houghton Mifflin, 1909.

Webb, Stephen H. On God and Dogs: A Christian Theology of Compassion for Animals. New York: Oxford U P, 2002. 